\title{
Perceptions of genetic discrimination among at-risk relatives of colorectal cancer patients
}

Kira A. Apse, $S c M^{1}$, Barbara B. Biesecker, $M S^{2}$, Francis M. Giardiello, $M D^{3}$, Barbara P. Fuller, $J D^{4}$, and Barbara A. Bernhardt, $M S^{5}$

\begin{abstract}
Purpose: To explore the concerns of at-risk relatives of colorectal cancer patients about genetic discrimination and their awareness of current legislative protections. Methods: A questionnaire was sent to unaffected individuals with a family history of colorectal cancer who had enrolled in the Johns Hopkins Hereditary Colorectal Cancer Registry $(N=777)$. Results: Of the 470 respondents, approximately half rated their level of concern about genetic discrimination as high. The majority of respondents, $79 \%$, learned about genetic discrimination from at least one media source (television, newspapers, magazines, and radio). If they were to pursue genetic testing, respondents with a higher level of concern about genetic discrimination would be significantly more likely to pay out of pocket, use an alias, or ask for test results to be excluded from their medical record. Awareness and understanding of legislation regarding genetic discrimination was found to be minimal. Conclusion: Findings from this study demonstrate the negative effect of concerns about genetic discrimination on decisions about utilization of genetic services. Stronger legislative protections against genetic discrimination and increased public education through the scientific community and media sources are needed. Genet Med 2004:6(6):510-516.
\end{abstract}

Key Words: genetic discrimination, genetic testing, legislation, media, colorectal cancer

Remarkable advancements in gene discovery and the development of genetic tests hold great promise for revolutionizing the practice of medicine. Accompanying these achievements, however, is the potential for misuse of genetic information. Due to the personal and predictive nature of genetic information, concerns have been raised about access to genetic information by insurers and employers. The term "genetic discrimination" has been used to describe the differential treatment of individuals or their relatives based on actual or presumed genetic differences as opposed to discrimination based on phenotype. ${ }^{1}$ Little is known about the nature and extent of genetic discrimination despite a decade of debate among researchers and policy makers. Several anecdotal cases of genetic discrimination have been documented ${ }^{1-3}$ but few have been filed with the courts. Well-publicized cases include the Equal Employment Opportunity Commission (EEOC) case against Burlington Northern Santa Fe Railroad ${ }^{4,5}$ and that of Terri Sergeant

\footnotetext{
From the ${ }^{1}$ Division of Neurogenetics, Beth Israel Deaconess Medical Center, Boston, Massachusetts; ${ }^{2}$ Social and Behavioral Research Branch, National Human Genome Research Institute, Bethesda, Maryland; ${ }^{3}$ Division of Gastroenterology, Department of Medicine, The Johns Hopkins University School of Medicine, Baltimore, Maryland; ${ }^{4}$ Policy and Program Analysis Branch, National Human Genome Research Institute, Bethesda, Maryland; and the ${ }^{5}$ Division of Medical Genetics, University of Pennsylvania School of Medicine, Philadelphia, Pennsylvania.

Kira Apse, 77 Avenue Louis Pasteur, NRB-266, Boston, MA 02115. E-mail: kapse@bidmc.harvard.edu.

Received: June 8, 2004.

Accepted: June 11, 2004
}

DOI: 10.1097/01.GIM.0000144013.96456.6C who was fired by her employer due to the costs of preventative treatment for $\alpha 1$-antitrypsin deficiency. ${ }^{6}$

Several studies have demonstrated concerns about genetic discrimination in the general population as well as in those affected with genetic disorders and their families. ${ }^{7-9}$ Fear of genetic discrimination has been cited as a reason that patients decline genetic counseling and testing for conditions including cancer, ${ }^{10-15}$ Huntington's Disease, ${ }^{16,17}$ and Fragile X syndrome. ${ }^{9}$ The Health Insurance Association of America maintains that public concerns are unwarranted as health insurers are not misusing genetic information, and that current federal law already provides sufficient protections. ${ }^{18}$ One study on the effectiveness of state genetic discrimination laws concluded that a person who is presymptomatic for a serious genetic condition faces little or no difficulty in obtaining health insurance. ${ }^{18,19}$

Protections against genetic discrimination are afforded through both federal and state legislation. The Health Insurance Portability and Accountability Act of 1996 (HIPAA) provides some protection against genetic discrimination, such as prohibiting the use of genetic information in denying or limiting health insurance coverage for members of a group plan. Forty-one states have enacted legislation on genetic discrimination in health insurance and thirty-one states have enacted legislation concerning the workplace. ${ }^{20}$ At the federal level, the Americans with Disabilities Act (ADA) is also felt to provide some protection from genetic discrimination by employers; however, this has not been tested in the courts. Additionally, Executive Order 13145 prohibits federal government agencies from obtaining or using genetic information in hiring and pro- 
motion decisions. Most recently, the U.S. Senate passed the "Genetic Information Nondiscrimination Act of 2003" which, if enacted, would close some of the loopholes left by HIPAA. At the time of publication, the House had not considered this Act.

Because of the reported high level of concern about genetic discrimination despite legislative protections and few documented cases, we explored the concerns of at-risk relatives of colorectal cancer patients about genetic discrimination and the potential effect on utilization of genetic services. Additionally, we examined awareness and understanding of current state and federal legislation addressing genetic discrimination.

\section{MATERIALS AND METHODS}

\section{Participants and procedures}

A questionnaire was mailed in May 2002 to 777 participants identified from the Johns Hopkins Hereditary Colorectal Cancer Registry. Eligible individuals were those at least 18 years old with a family history of colorectal cancer (CRC) and without a personal history of CRC or known associated cancers. All eligible participants received a personalized letter of invitation explaining the purpose of the study, a questionnaire and a stamped return envelope from the Johns Hopkins Hereditary Colorectal Cancer Registry. Nonrespondents received a second mailing of all materials four weeks later.

\section{Measures}

A 10-page questionnaire was designed by the researchers for this study. Sociodemographic and medical information, including respondents' personal and family history of colorectal cancer and/or polyps, were collected. Respondents were asked to rate their level of concern about genetic discrimination on a 5-point Likert scale, and to describe the reasons for their concern or lack of concern. An open-ended question allowed respondents to describe any personal or family experience with genetic discrimination. Through multiple choice and Likert scale questions, respondents indicated awareness of and sources of information about genetic discrimination and legislation. Likert scale questions were also posed to determine respondents' hypothetical decisions about utilization of genetic services.

\section{Data analysis}

Data were stored and analyzed using SPSS 10.0 (Statistical Package for the Social Sciences). Descriptive statistics are reported for respondents' level of concern about genetic discrimination, source of information about genetic discrimination, interest in and utilization of genetic services, and awareness and impressions of genetic nondiscrimination legislation. Bivariate ordinal regression was performed to determine if decisions about utilization of genetic services were associated with level of concern about genetic discrimination. For each set of ordinal regressions, odds ratio estimates, corresponding 95\% confidence intervals, and two-sided $P$-values were computed $(P<0.05$ was considered statistically significant $)$.

\section{RESULTS}

\section{Response rate and sample description}

Of the original 777 questionnaires sent, 544 were returned and 23 were undeliverable. Of those questionnaires returned and completed, 22 surveys were excluded from analysis because respondents either did not complete the family history section $(N=10)$, had a personal history of colorectal cancer $(N$ $=5)$, or did not have a family history of colorectal cancer $(N=$ 7). An additional 52 questionnaires were returned not completed, as the recipient declined to participate. Reasons cited were no time, no interest, concerns about privacy, other priorities, and compromised health. Thus, a response rate of $62 \%$ $(N=470 / 754)$ was achieved.

A description of the sample is presented in Table 1. More than half of the respondents were in the age range of 41 to 60 years and had a college degree or above. Reflecting the composition of the registry, respondents were predominantly female, Caucasian, and married with children. There were respondents from 48 states.

Table 1

Respondents' Sociodemographic Information $(N=470)$

\begin{tabular}{|c|c|}
\hline \multicolumn{2}{|l|}{ Age (yrs) } \\
\hline $19-40$ & $16.8 \%$ \\
\hline $41-60$ & $58.1 \%$ \\
\hline $61+$ & $25.1 \%$ \\
\hline \multicolumn{2}{|l|}{ Gender } \\
\hline Female & $79.1 \%$ \\
\hline Male & $20.9 \%$ \\
\hline \multicolumn{2}{|l|}{ Race } \\
\hline Caucasian & $94.9 \%$ \\
\hline Hispanic & $1.9 \%$ \\
\hline African-American & $1.5 \%$ \\
\hline Asian & $0.6 \%$ \\
\hline Mixed/Other & $1.1 \%$ \\
\hline \multicolumn{2}{|l|}{ Education } \\
\hline High school or less & $15.9 \%$ \\
\hline Some college & $23.0 \%$ \\
\hline College graduate + & $61.1 \%$ \\
\hline \multicolumn{2}{|l|}{ Marital status } \\
\hline Single & $10.3 \%$ \\
\hline Married & $70.9 \%$ \\
\hline Separated/Divorced & $13.6 \%$ \\
\hline Widowed & $5.2 \%$ \\
\hline \multicolumn{2}{|l|}{ Children } \\
\hline Yes & $81.2 \%$ \\
\hline No & $18.8 \%$ \\
\hline
\end{tabular}




\section{Concerns about genetic discrimination}

A definition of genetic discrimination was provided in the survey so that all participants would have an understanding of the concept. The definition read: "When people or organizations make unfair decisions about someone who is currently healthy based on genetic information (results of genetic testing or family history information)." To determine the extent of concern about genetic discrimination, respondents were asked to rate their level of concern on a 5-point Likert scale (Fig. 1). Level 1 was labeled as "not concerned" and level 5 was labeled as "very concerned.” Approximately half of respondents, 45\%, rated their level of concern as high, at level 4 or 5 . About a third, $37 \%$, rated their level of concern as lower, at level 2 or 3. Notably, $18 \%$ of respondents indicated no concern about genetic discrimination, corresponding to level 1 . Reasons provided for lack of concern included trust in insurers, employers, health care providers or legislation $(N=12)$, age/medicare coverage $(N=14)$, belief that everyone has some level of risk $(N=8)$, that the benefits of genetic testing outweigh the risks $(N=3)$, and never having thought about it before $(N=13)$.

\section{Experiences with genetic discrimination}

Approximately 7\% of respondents reported that they or a family member had experienced genetic discrimination. Respondents' open-ended descriptions of their experiences were categorized as rated/higher premiums for life or long-term care insurance $(N=7)$, denial of health or life insurance coverage $(N=4)$, difficulty obtaining health or life insurance coverage $(N=4)$, problems with health insurance coverage $(N=$ $2)$, denial of coverage for screening $(N=5)$, and perceived inability to change jobs $(N=1)$. Some of the reported experiences with discrimination were not related to colorectal cancer, but to conditions such as arthritis, diabetes, heart conditions, Charcot-Marie Tooth syndrome, and hip dysplasia.
With the limited information provided, it is difficult to unequivocally determine if any of the reported experiences involve actual genetic discrimination.

\section{Source of information about genetic discrimination}

The majority of respondents, $68 \%$, were aware of genetic discrimination before receiving the survey. Those aware of genetic discrimination most commonly received their information from media sources, including television (58\%), newspapers (58\%), magazines (43\%), and radio (16\%) (Fig. 2). Learning about genetic discrimination from at least one media source was reported by $79 \%$ of respondents. Less often, respondents learned about genetic discrimination from a doctor (15\%), genetic counselor (10\%), other health care professional $(5 \%)$, or researcher $(3 \%)$. "Other" sources of information mentioned by $7 \%$ of respondents included "college," "scientific journals." "insurance agent," "legislators," "common sense," and a "family member."

\section{Decisions about utilization of genetic services}

The majority of respondents, $80 \%$, were interested in pursuing genetic testing for colorectal cancer risk. Although 16\% of the study population had been previously offered genetic testing, $8 \%$ chose to undergo testing. Respondents were asked about their previous or hypothetical decision-making concerning genetic testing (Table 2). Sixty-two percent reported that they would be likely or very likely to submit charges for genetic testing to their insurance company, whereas 35\% would be likely or very likely to pay out of pocket to avoid submitting a claim. Fifteen percent would be likely or very likely to use an alias so that test results could not be connected with their name. The vast majority of respondents, $92 \%$, would be likely or very likely to share their genetic information with

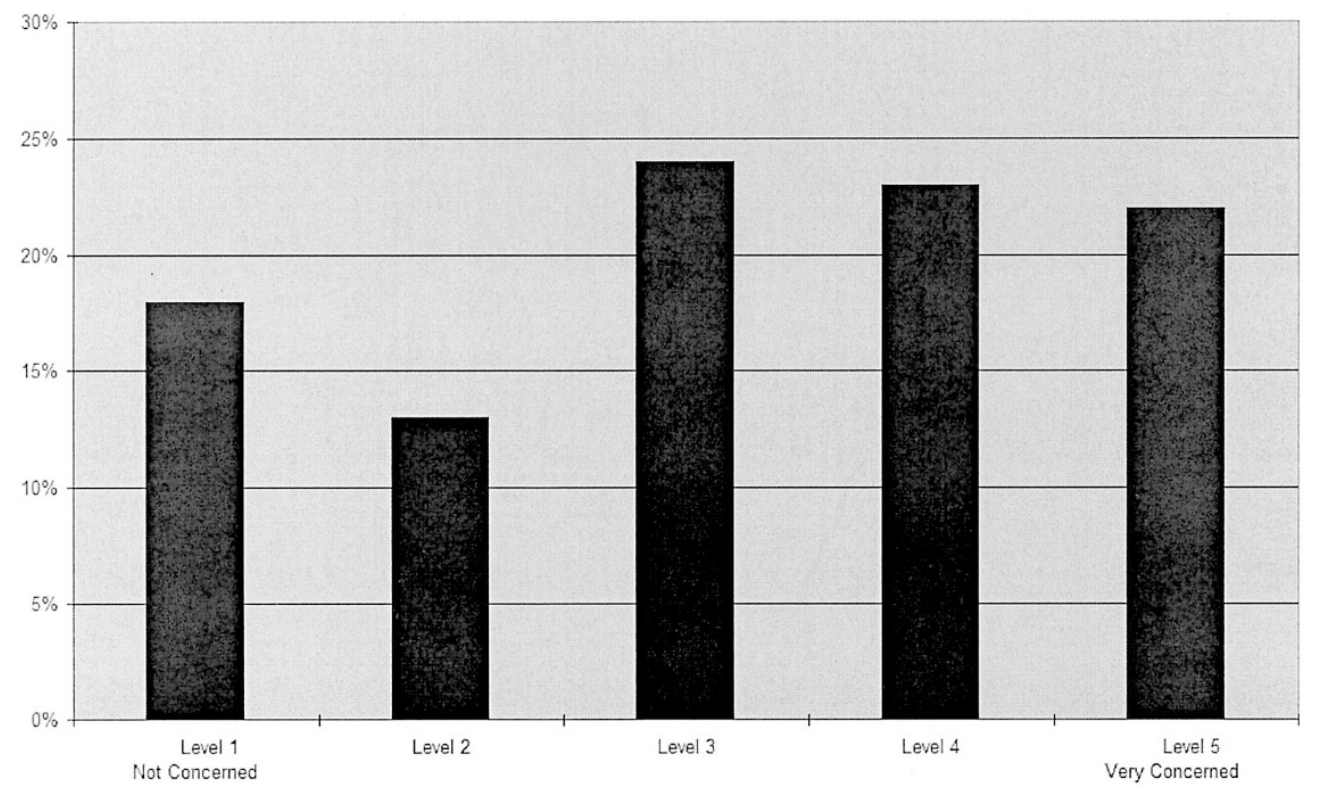

Fig. 1. Respondents' level of concern about genetic discrimination $(N=455)$. 


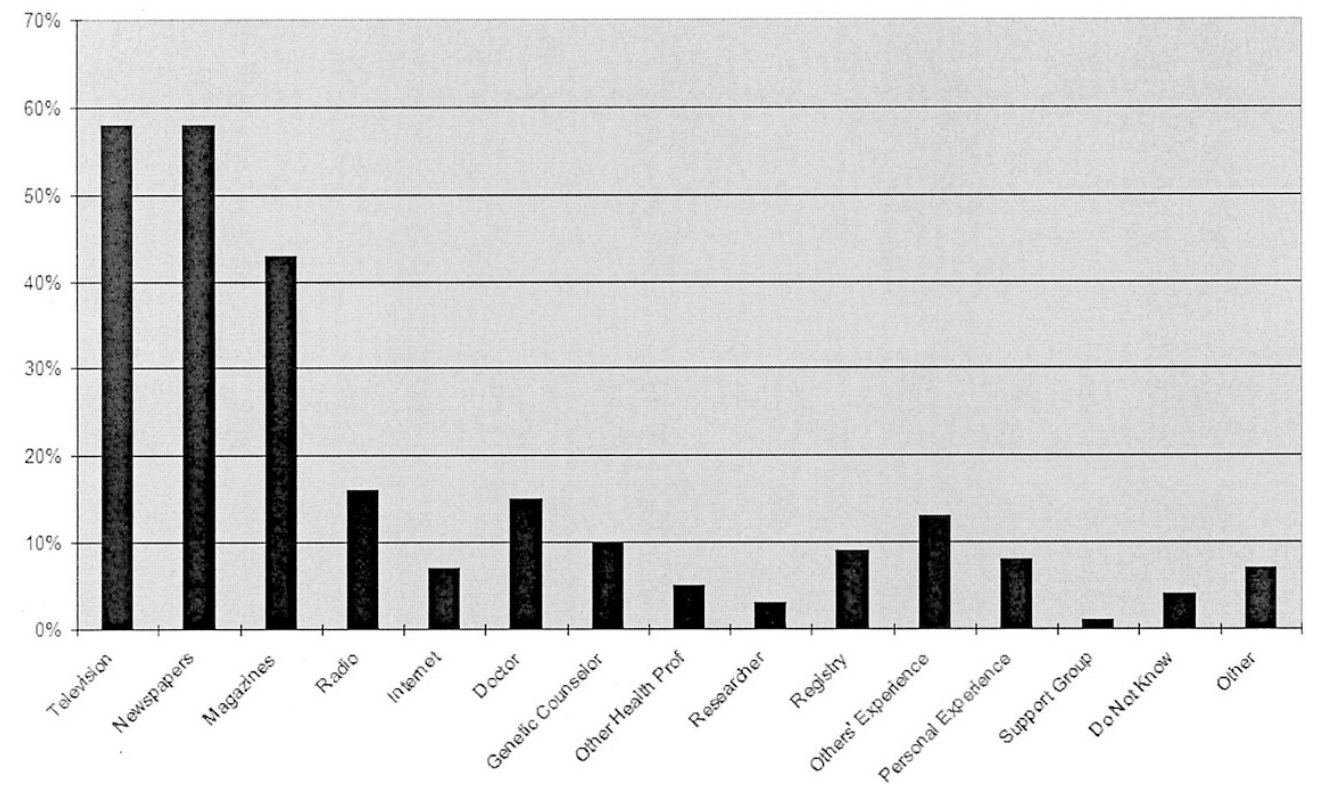

Fig. 2. Respondents' source of information about genetic discrimination $(N=312)$.

doctors. However, $47 \%$ would be likely or very likely to ask that genetic test results be excluded from their medical record.

Bivariate ordinal regression tests revealed a statistically significant association between higher level of concern about genetic discrimination and all five decisions related to utilization of genetic services $(P<0.001)$ (Table 3$)$. Respondents who were more concerned about genetic discrimination would be 0.67 times or $33 \%$ less likely to submit the charges for genetic testing to their insurance company. Those who were more concerned would be 1.5 times more likely to pay out of pocket and use an alias when undergoing genetic testing. Respondents with a higher level of concern would be 0.74 times or $26 \%$ less likely to share their genetic information with doctors, and would be 1.6 times more likely to ask for genetic test results to be excluded from their medical record.

\section{Awareness and impressions of genetic nondiscrimination legislation}

Respondents had minimal awareness of current state and federal laws protecting against genetic discrimination. The ma- jority, $88 \%$, were not aware of any federal legislation regarding genetic discrimination. When asked specifically about the Health Insurance Portability and Accountability Act (HIPAA), $73 \%$ had never heard of the legislation. Regarding the existence of laws in their home state, $96 \%$ of respondents did not know, $1 \%$ responded that their state did not have a law, and 3\% that their state did have a law addressing genetic discrimination.

Respondents were considered to be aware of genetic nondiscrimination legislation if they had knowledge of either federal or state laws. Among those aware of the legislation $(N=140)$, understanding was limited as 59\% reported that they did not understand the laws at all (Table 4). Approximately half responded that that the legislation does "not at all" provide adequate protection against employment and insurance discrimination. Those who were considered the most aware of legislation $(N=92)$, answering either "to some extent" or "to a great extent" about how much they had heard or understood about the legislation, were significantly more likely to have a higher educational level $(P=0.005)$ and to have undergone genetic testing $(P=0.04)$.

Table 2

Respondents' Decisions about Utilization of Genetic Services $(N=457)$

\begin{tabular}{|c|c|c|c|c|}
\hline $\begin{array}{l}\text { If you were to have or ever had genetic testing, how likely is } \\
\text { it that you would: }\end{array}$ & Very unlikely & Unlikely & Likely & Very likely \\
\hline $\begin{array}{l}\text { 1. Submit the charges for genetic testing to your insurance } \\
\text { company? }\end{array}$ & $22 \%$ & $16 \%$ & $17 \%$ & $45 \%$ \\
\hline $\begin{array}{l}\text { 2. Pay "out of pocket" for genetic testing to avoid } \\
\text { submitting a claim to your health insurance company? }\end{array}$ & 45 & 20 & 18 & 17 \\
\hline $\begin{array}{l}\text { 3. Use a fake name so that your genetic test results could } \\
\text { not be connected to you? }\end{array}$ & 71 & 14 & 8 & 7 \\
\hline 4. Share your genetic information with your doctors? & 2 & 6 & 17 & 75 \\
\hline $\begin{array}{l}\text { 5. Ask for your genetic test results to be excluded from your } \\
\text { medical record? }\end{array}$ & 36 & 17 & 20 & 27 \\
\hline
\end{tabular}




\section{Source of information about genetic nondiscrimination legislation}

Those who were aware of laws regarding genetic discrimination identified the source of their information (Fig. 3). Respondents cited media sources most often, including newspapers $(47 \%)$, television $(42 \%)$, magazines $(27 \%)$, and radio (22\%). Approximately $57 \%$ indicated at least one form of media as their source of information about genetic nondiscrimination laws. Less often cited sources were a doctor $(5 \%)$, genetic counselor $(4 \%)$, researcher $(4 \%)$, and other health care professional (6\%). "Other" sources of information about the legislation mentioned by $10 \%$ of respondents were "employer," "medical literature," "legal literature," "college," and a "long-term care insurance" brochure.

\section{DISCUSSION}

While debate will likely continue regarding the nature and extent of genetic discrimination, significant concern about the misuse of genetic information by insurers and employers is undeniable. This study revealed substantial concern about genetic discrimination among members of a hereditary colorectal cancer registry. Few respondents reported that they or a family member had actually experienced genetic discrimination and none of the described experiences, though limited in detail, provide a clear-cut example. Thus, our data support previous studies suggesting that fear of discrimination may be discrepant with actual experience. ${ }^{9,15}$

The most frequently cited source of information about genetic discrimination in our study was the media, whereas

Table 3

Associations between Level of Concern and Decisions about Utilization of Genetic Services

\begin{tabular}{llll}
\hline & OR & CI & $P$ value \\
\hline Submit to insurance (Q1) & 0.67 & $(0.58-0.76)$ & $<0.001$ \\
Pay out of pocket (Q2) & 1.5 & $(1.3-1.7)$ & $<0.001$ \\
Use fake name (Q3) & 1.5 & $(1.3-1.8)$ & $<0.001$ \\
Share genetic information with doctors (Q4) & 0.74 & $(0.63-0.87)$ & $<0.001$ \\
Exclude from medical record (Q5) & 1.6 & $(1.4-1.8)$ & $<0.001$ \\
\hline
\end{tabular}

Independent variable is level of concern; dependent variables are decisions about utilization of genetic services. health care professionals were mentioned less often. This is consistent with genetic counselors' reports that many patients hear about genetic discrimination through the media. ${ }^{21}$ In particular, several genetic counselors described a 1998 Parade Magazine article as the source of cancer patients' information and concern. Information provided by media sources is often minimal and dramatized. An analysis of media content surrounding the announcement of the human genome mapping found that discussion of privacy and discrimination, although frequently mentioned as a risk of genetic research, was generally limited in scope and depth. ${ }^{8}$ The result may be public misconception about the magnitude of risks and increased concern about genetic discrimination.

Interest in genetic testing was high in this population of individuals at increased risk for developing cancer, as supported by other studies. ${ }^{22,23}$ However, interest was tempered by concerns about genetic discrimination. Hypothetical decisions about utilization of genetic services were significantly influenced by a higher level of concern about genetic discrimination. Those with higher levels of concern would be more likely to pay out of pocket and use an alias when undergoing genetic testing. To avoid submitting an insurance claim, more than a third of respondents would pay out of pocket for genetic testing. As genetic testing can be costly, those who can not independently afford testing and are concerned about discrimination risks will be less likely to pursue genetic testing even when interested in obtaining the results. Some respondents would be likely to be tested using an alias to lessen the risks of genetic discrimination. In one study, interviews with genetics specialists who facilitated pseudonymous and anonymous genetic testing for Huntington's disease revealed that the more information a patient withheld, the less comfortable the provider felt and the more difficult and time-consuming it was to document family history, provide genetic counseling, and obtain informed consent. ${ }^{24}$ Thus, patients' desire for privacy protection may hinder the relationship between the provider and patient, and make accurate risk assessment and provision of genetic services problematic.

Respondents with a higher level of concern about genetic discrimination would be less likely to share genetic information with doctors and more likely to ask for results to be excluded from their medical record. Although the majority would share the results with doctors, approximately half would

Table 4

Understanding and Impressions of Laws Regarding Genetic Discrimination $(N=140)$

\begin{tabular}{|c|c|c|c|}
\hline If you are aware of the laws regarding genetic discrimination: & Not at all & To some extent & To a great extent \\
\hline 1. How much have you heard about laws regarding genetic discrimination? & $35 \%$ & $61 \%$ & $4 \%$ \\
\hline 2. How well do you feel you understand the laws regarding genetic discrimination? & 59 & 37 & 4 \\
\hline $\begin{array}{l}\text { 3. Do you think there is adequate protection in the laws to prevent employment discrimination based } \\
\text { on genetic information? }\end{array}$ & 47 & 48 & 5 \\
\hline $\begin{array}{l}\text { 4. Do you think there is adequate protection in the laws to prevent health insurance discrimination } \\
\text { based on genetic information? }\end{array}$ & 56 & 40 & 4 \\
\hline 5. Do you feel adequately protected by the laws against genetic discrimination? & 53 & 43 & 4 \\
\hline
\end{tabular}




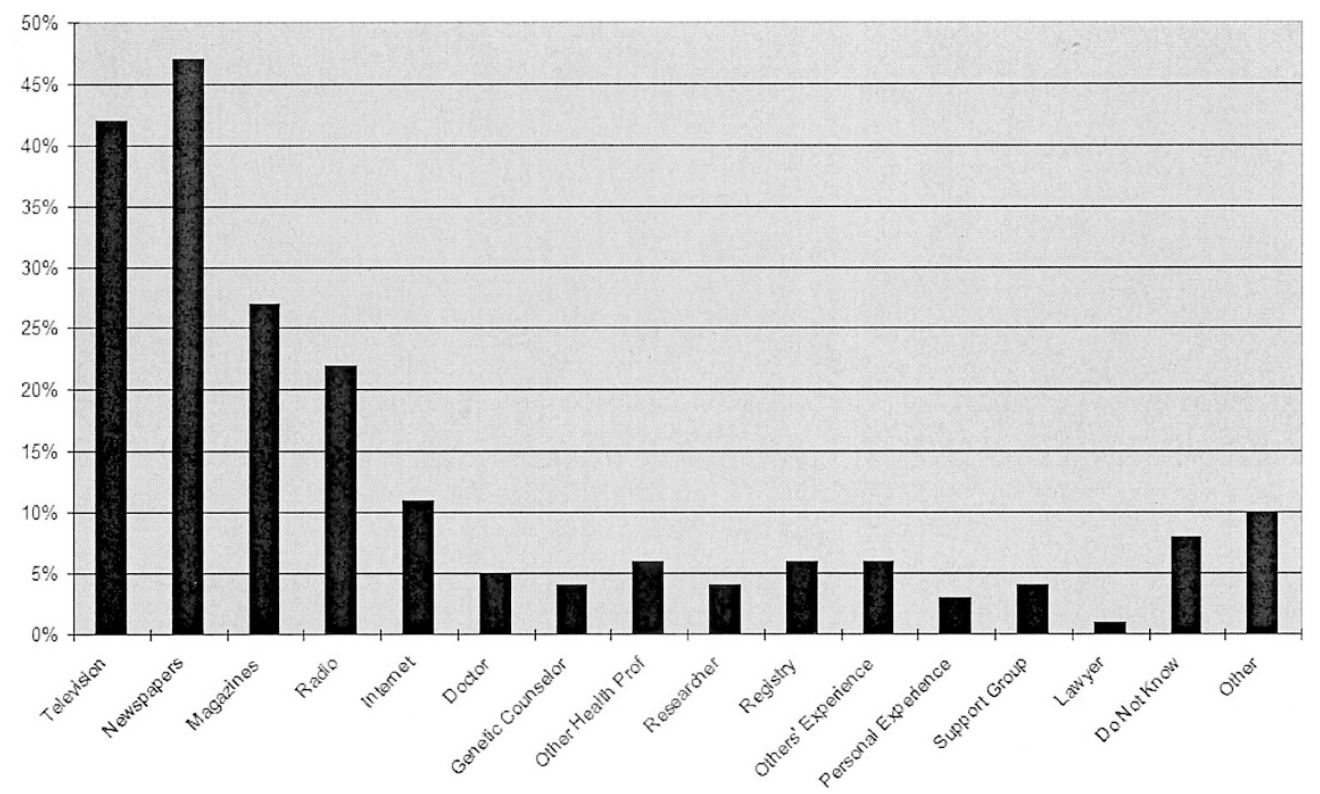

Fig. 3. Respondents' source of information about genetic nondiscrimination legislation $(N=110)$.

ask for the test results to be excluded from their medical record. Withholding genetic information from health care professionals and from inclusion in their medical record may reduce the probability of patients' receiving appropriate and comprehensive care, although this has not been determined through research.

By joining a research registry and accordingly demonstrating interest in genetics and health issues, one might expect registry members to be more aware of relevant legislation than the general public. However, the vast majority of respondents were unaware of the federal or state laws. Even among those who were familiar with the legislation, more than half did not understand the laws. This may be related to their source of information about genetic nondiscrimination legislation, which was most often the media. Presumably little detail and explanation about the legislation was supplied by the media sources due to inherent time and/or space constraints.

The belief that the legislation does not offer adequate protection against insurance and employment discrimination was held by the majority of those respondents who were aware of the legislation. Another study documented reasons that individuals do not feel adequately protected, with concerns stemming from unenforceability, lack of protection in some states, and worry that the law could be changed or revoked in the future. ${ }^{14}$ Interestingly, awareness of legislation did not significantly affect level of concern about genetic discrimination. This may be due to respondents' lack of confidence in the current legislation to adequately protect against discrimination, as well as an overall limited understanding of the protections involved.

Findings from this study suggest a clear need to educate the public about existing legislative protections against genetic discrimination. Media sources, relied on by much of the public for health information, provide insufficient information about the risks and legislative protections regarding genetic discrimination. Consequently, accurate and comprehensible information must be supplied by the scientific and medical communities through patient interaction, and by collaboration with the media to better inform the public.

In addition, effective and enforceable protections through legislation are necessary to increase the confidence of both health care professionals and patients that genetic discrimination cannot occur. If enacted, the legislation currently pending before the U.S. House of Representatives would provide comprehensive protections against discrimination in insurance and employment. The legislation applies to health insurance markets and bans the collection and use of genetic information for purposes of underwriting. Additionally, the legislation prohibits the use of genetic information in employment decisions as well as specifically prohibits employers from requesting, requiring, or purchasing genetic information of employees or family members, but would allow employers to conduct genetic monitoring of the biological effects of toxic substances in the workplace. ${ }^{25,26}$ Leaders in the genetics field have strongly endorsed this legislation as it successfully addresses the concerns of the biomedical research and health communities. ${ }^{27}$ Enacted legislation should provide assurances that individuals at heightened risk for genetic conditions and for whom genetic test results may offer beneficial health management information do not have to fear loss of insurance or employment. Once further legislation has been established, the scientific community and the media should inform the public about the increased protections to allay concerns. Lastly, more dialogue between insurers and health care professionals may reduce the division of views about the risks of genetic discrimination and the most effective and fair means of protecting patients.

There are several limitations to this study to be considered. First, the study sample was composed of individuals who volun- 
tarily enrolled in a high-risk research registry and, therefore, results may not be not generalizable to all individuals with a family history of colorectal cancer. Those who join a research registry and provide family history information may differ in their concerns and decisions regarding genetic discrimination from other individuals. People with the most concern about genetic discrimination may not have been included in the study population, as these individuals would be unlikely to contact the registry initially. In addition, because only a small percentage of the respondents and their family members had already pursued genetic testing, there was limited opportunity for actual genetic discrimination to occur. Further limitations are that the registry population is an ethnically homogeneous sample, and females and those with higher education are over-represented.

\section{Conclusions}

Although the prevalence of genetic discrimination is unknown, significant public concern exists and should be addressed through education and legislative protections. As indicated by our study findings, the disproportionate fear of genetic discrimination relative to actual experience may be due in part to individuals' reliance on information provided by the media as well as lack of confidence in or familiarity with the existing legislative protections to prevent genetic discrimination. This study documented that concerns about genetic discrimination might influence the utilization of genetic services. Future research should explore how exaggerated concerns about genetic discrimination might be reduced so as to eliminate barriers to utilization of potentially valuable genetic services. Research could focus on the possible impact of modifying or supplementing media messages, educating the public about existing legislation, or identifying effective means of reassuring those with exaggerated fears about genetic discrimination.

\section{ACKNOWLEDGMENTS}

The research was funded by the Intramural Research Program of the National Human Genome Research Institute. The study was approved by the National Human Genome Research Institute Institutional Review Board (Protocol 02-HG-0163) and the Johns Hopkins Bloomberg School of Public Health Committee on Human Research (Protocol H.30.02.02.06.A). We thank the members of the Hereditary Colorectal Cancer Registry for participating in our survey study. In addition, we are grateful to the staff of the Hereditary Colorectal Cancer Registry for their assistance in study implementation.

\section{References}

1. Geller LN, Alper JS, Billings PR, Barash CI, Beckwith J, Natowicz MR. Individual, family, and societal dimensions of genetic discrimination: a case study analysis. Sci Eng Ethics 1996;2:71-88.
2. Billings PR, Kohn MA, de Cuevas M, Beckwith J, Alper JS, Natowicz MR. Discrimination as a consequence of genetic testing. Am J Hum Genet 1992;50:476-482.

3. Lapham EV, Kozma C, Weiss JO. Genetic discrimination: perspectives of consumers. Science 1996;274:621-624.

4. The U.S. Equal Employment Opportunity Commission: EEOC Settles ADA Suit Against BNSF For Genetic Bias, April 18, 2001. Available at: http://www.eeoc.gov/ press/4-18-01.html. Accessed June 8, 2004.

5. Rothenberg KH, Terry SF. Human genetics. Before it's too late-addressing fear of genetic information. Science 2002;297:196-197.

6. Pink Slip in Your Genes. Available at: http://www.alphal.org/programs/newsmakers_pinkslip.htm. Accessed June 8, 2004.

7. Harris Poll 1995, \#34

8. Tambor ES, Bernhardt BA, Rodgers J, Holtzman NA, Geller G. Mapping the human genome: an assessment of media coverage and public reaction. Genet Med 2002;4 31-36.

9. Wingrove KJ, Norris J, Barton PL, Hagerman R. Experiences and attitudes concerning genetic testing and insurance in a Colorado population: a survey of families diagnosed with fragile X syndrome. Am J Med Genet 1996;64:378-381.

10. Lerman C, Marshall J, Audrain J, Gomez-Caminero A. Genetic testing for colon cancer susceptibility: Anticipated reactions of patients and challenges to providers. Int J Cancer 1996;69:58-61.

11. Phillips KA, Warner E, Meschino WS, et al. Perceptions of Ashkenazi Jewish breast cancer patients on genetic testing for mutations in BRCA1 and BRCA2. Clin Genet 2000;57:376-383.

12. Armstrong K, Calzone K, Stopfer J, Fitzgerald G, Coyne J, Weber B. Factors associated with decisions about clinical BRCA1/2 testing. Cancer Epidemiol Biomarkers Prev 2000;9:1251-1254.

13. Kinney AY, DeVellis BM, Skrzynia C, Millikan R. Genetic testing for colorectal carcinoma susceptibility: focus group responses of individuals with colorectal carcinoma and first-degree relatives. Cancer 2001;91:57-65.

14. Geer KP, Ropka ME, Cohn WF, Jones SM, Miesfeldt S. Factors influencing patients' decisions to decline cancer genetic counseling services. J Genet Couns 2001;10:2540.

15. Peterson EA, Milliron KJ, Lewis KE, Goold SD, Merajver SD. Health insurance and discrimination concerns and BRCA1/2 testing in a clinic population. Cancer Epidemiol Biomarkers Prev 2002;11:79-87.

16. Quaid KA, Morris M. Reluctance to undergo predictive testing: the case of Huntington disease. Am J Med Genet 1993;45:41-45.

17. Codori AM, Hanson R, Brandt J. Self-selection in predictive testing for Huntington's disease. Am J Med Genet 1994;54:167-173.

18. Health Insurance Association of America. Health Insurers Say Genetic Discrimination Bill 'Premature', 2003. Available at: http://www.hiaa.org/search/content.cfm? ContentID=23567. Accessed June 8, 2004.

19. Hall MA, Rich SS. Laws restricting health insurers' use of genetic information: impact on genetic discrimination. Am J Hum Genet 2000;66:293-307.

20. NHGRI Issue Update: Health Insurance and Employment Discrimination, October 2003. Available at: http://www.genome.gov. Accessed June 8, 2004.

21. Hall MA, Rich SS. Genetic privacy laws and patients' fear of discrimination by health insurers: the view from genetic counselors. J Law Med Ethics 2000;28:245-257.

22. Lerman C, Daly M, Masny A, Balshem A. Attitudes about genetic testing for breastovarian cancer susceptibility. J Clin Oncol 1994;12:843-850.

23. Petersen GM, Larkin E, Codori AM, et al. Attitudes toward colon cancer gene testing: survey of relatives of colon cancer patients. Cancer Epidemiol Biomarkers Prev 1999;8:337-344.

24. Visintainer CL, Matthias-Hagen V, Nance MA. Anonymous predictive testing for Huntington's disease in the United States. Genet Test 2001;5:213-218.

25. S. 1053, Genetic Information Nondiscrimination Act of 2003. Available at: http:// thomas.loc.gov/cgi-bin/query/C?c108:./temp/ c108gL6kqN. Accessed June 8, 2004.

26. Genetic Information Nondiscriminaton Act of 2003 Summary of Bipartisan Agreement. Available at: http://www.americanbenefitscouncil.org/documents/gia_bipart_ summary.htm Accessed June 8, 2004.

27. Collins FS, Watson JD. Genetic discrimination: time to act. Science 2003;302:745 